\title{
ROSTO E RESPONSABILIDADE NA FILOSOFIA DA ALTERIDADE EM EMMANUEL LEVINAS
}

Face and Responsibility in Emmanuel Levinas Philosophy of Otherness

Daniel Ribeiro de Almeida Chacon*

Resumo: O presente artigo quer apresentar os aspectos fundamentais da noção de rosto presentes na ética da alteridade proposta por Emmanuel Levinas. Nesse sentido, a partir da categoria da alteridade, a questão da responsabilidade radical por outrem irá emergir como importante elemento da filosofia levinasiana. Com efeito, devido à originalidade e a influência deste novo caminho, percebe-se a urgência de transcender as solitudes discursivas, repensando o lugar do outro na reflexão filosófica. As considerações desta pesquisa se põem na perspectiva de que a relação entre ética e responsabilidade por outrem constitui um complexo e essencial drama para o campo de pesquisa filosófica.

Palavras-chave: Alteridade, Emmanuel

\begin{abstract}
This paper proposes to present the primary aspects of the notion of face present in the ethics of otherness by Emmanuel Levinas. Accordingly, from this category, the issue of radical responsibility for others will emerge as an important element of Levinasian philosophy. Indeed, due to the originality and influence of this new way, it urges to transcend the discursive solitudes, rethinking the place of the other in philosophical reflection. Considerations found in this research are from the perspective of the relationship between ethics and responsibility for others is a complex and essential drama to the field of philosophical inquiry.
\end{abstract}

Keywords: Otherness, Emmanuel Levinas, Face of Levinas, Rosto do Outro

\footnotetext{
* Mestrando em Filosofia na Faculdade Jesuíta de Filosofia e Teologia (bolsista pela CAPES) dan.chacon@yahoo.com.br
}

\begin{tabular}{|c|c|l|l|c|c|}
\hline intuitio & $\begin{array}{c}\text { ISSN } \\
1983-4012\end{array}$ & Porto Alegre & Vol.8 $-\mathrm{N}^{\mathrm{o} .2}$ & $\begin{array}{c}\text { Dezembro } \\
2015\end{array}$ & p.15-24 \\
\hline
\end{tabular}




\section{Introdução}

O drama ético constitui sempre uma indispensável questão para a sociedade. As formulações desta intriga se relacionam diretamente aos problemas que afetam a vida humana em seus aspectos social, político, econômico, psicológico, existencial e em todas as demais facetas da experiência humana.

$\mathrm{Na}$ contemporaneidade, a ética da alteridade ${ }^{1}$ tem surgido como um novo caminho para se pensar a construção do conhecimento e as relações humanas. A alteridade irrompe como denuncia profética aos modelos ético-epistemológicos solipsistas, egoístas e desumanizadores presentes na sociedade hodierna.

A partir da consciência de que o eu é um ser em relação social com outros seres, Levinas irá propor a ética como fonte de sentido. Nessa perspectiva, ética e saber convergem para uma nova epistemologia. O conhecimento para além de uma abordagem totalitária, egológica e especulativa, emerge do rosto $^{2}$ em plena inópia do outro. Dessa forma, o outro assume a primazia na história do pensamento.

Destarte, Levinas propõe um humanismo que encontra, em meio à penúria do rosto do outro, um vestígio de Deus. Em contato com o Infinito o eu é interpelado a assumir uma conduta de responsabilidades radical, que estabelece o outro como prioridade absoluta - alteridade.

Nesse sentido, serão descritos ao longo deste artigo os aspectos primários dessa nova epistemologia. Todavia, cumpre esclarecer que o esforço aqui despendido para apresentar, em linhas gerais, essa complexa questão não deve ser interpretado como uma abordagem exaustiva ou, mesmo conclusiva, de todo o pensamento levinasiano

\section{Rosto}

A epistemologia levinasiana é um convite a pensar o outro sob o signo do rosto. Mas, em que consiste falar do rosto do outro? Qual o significado que se pode extrair diante de um rosto? Em sua reflexão, Levinas constrói um novo sentido para o rosto. Sua concepção de rosto vai além de uma pura descrição fenomenológica:

Quando se vê um nariz, os olhos, uma testa, um queixo e se podem descrever, é que nos voltamos para outrem como para um objeto. A melhor maneira de encontrar outrem é nem sequer atentar na cor dos olhos! Quando se observa a cor dos olhos, não se está em relação social com o outrem. A relação com o rosto

\footnotetext{
${ }^{1}$ A Alteridade será compreendida aqui como o estabelecimento do outro com ideal regulador da vida.

${ }^{2}$ Conforme será apresentado nesta investigação, o rosto, na filosofia levinasiana, está para além da forma "plástica". O rosto significa vida, alteridade absoluta, manifestação enigmática do Infinito.
}

\begin{tabular}{|c|c|c|c|c|c|}
\hline intuitio & $\begin{array}{c}\text { ISSN } \\
1983-4012\end{array}$ & Porto Alegre & Vol.8 $-\mathrm{N}^{\mathrm{o}} .2$ & $\begin{array}{c}\text { Dezembro } \\
2015\end{array}$ & p.15-24 \\
\hline
\end{tabular}


pode, sem dúvida, ser dominada pela percepção, mas o que é especificamente rosto é o que não se reduz a ele ${ }^{3}$

Levinas não se preocupa em realizar uma "representação" do rosto, mas procura demonstrar sua manifestação. Para ele, a face do outro transcende a forma "plástica". O rosto não se constitui apenas como uma mera oferta de dados. $\mathrm{O}$ rosto significa vida, alteridade absoluta, uma experiência reveladora.

A linguagem que a face do outro comunica não é simples imanência, mas transcendência, pois o outro está para além das percepções de sentidos e cognitivas do eu. Com efeito, nem mesmo as racionalidades empírica, racionalista ou mesmo positivista poderão apreender o significado da face do outro em sua totalidade.

Em Levinas, a face está além de qualquer juízo ou de qualquer opinião que a aprisione nas amarras da totalidade. Ela transcende toda possibilidade de tematização. A face rompe com qualquer horizonte com o qual ela possa ser identificada": "O rosto está presente na recusa de ser conteúdo. Nesse sentido, não poderá ser compreendido, isto é, englobado" 5 .

A escolha e utilização deste termo provém, possivelmente, da inspiração profética advinda da tradição hebraica, em que o termo hebraico comumente traduzido como rosto pode indicar também as várias formas da presença de YHWH. Destarte, é a partir dessa inspiração que Emmanuel Levinas irá descrever o rosto como manifestação enigmática do Infinito.

\section{Rosto e Infinito}

É intrigante a forma com que Emmanuel Levinas articula o conceito cartesiano de infinito, atribuindo-lhe um novo significando e estabelecendo-o como um dos pontos centrais de sua filosofia.

Segundo Descartes, a existência do eu é a única verdade não passível de dúvida. A partir dessa conclusão, ele levanta uma surpreendente questão: como explicar o fato de o eu, enquanto ser finito, poder conceber a ideia do infinito? Descartes responde a essa questão asseverando que apenas um ser infinito poderia criar a ideia de infinito. Dessa forma, ele conclui que além do eu existe outro ente, Deus ${ }^{6}$.

$\mathrm{Na}$ filosofia do rosto, Levinas atribui um novo significado à compreensão cartesiana do infinito, propondo que esta surge como uma experiência relacional. Nessa experiência, o outro não é visto como

\footnotetext{
${ }^{3}$ LEVINAS, Emmanuel. Ética e infinito. Tradução de João Gama. Lisboa: Ed. 70, 1982, p. 77.

${ }^{4}$ Cf. BUCKS, A Bíblia e a ética: A relação entre a filosofia e a Sagrada Escritura na obra de Emmanuel Levinas. São Paulo: Loyola, 1997, p. 109.

${ }^{5}$ LEVINAS, Emmanuel. Totalidade e infinito. Tradução de José Pinto Ribeiro. Lisboa: Edições 70, 2008, p. 188.

${ }^{6}$ Cf. MELO, Nélio Vieira de. A Ética da alteridade em Emmanuel Levinas. Porto Alegre: EDIPUCRS; Recife: INSAF, 2003, p. 115.
}

\begin{tabular}{|c|c|l|l|c|c|}
\hline intuitio & $\begin{array}{c}\text { ISSN } \\
1983-4012\end{array}$ & Porto Alegre & Vol.8 $-\mathrm{N}^{\mathrm{o} .2}$ & $\begin{array}{c}\text { Dezembro } \\
2015\end{array}$ & p.15-24 \\
\hline
\end{tabular}


"objeto" ou "coisa", mas como concretude do Infinito: "A ideia de Infinito, o infinitamente mais contido no menos, produz-se concretamente sob a aparência de uma relação com o rosto" ${ }^{7}$. Com efeito:

A ideia do Infinito não parte, pois de Mim, nem de uma necessidade do Eu que avalie exactamente os seus vazios. Nela, o movimento parte do pensado e não do pensador. [...] A ideia do Infinito revela-se, no sentido forte do termo. [...] O Infinito não é 'objecto' de um conhecimento - o que o reduziria à medida do olhar que contempla - mas o desejável, o que suscita o Desejo, isto é, que é abordável por um pensamento que a todo instante pensa mais do que pensa. $\mathrm{O}$ Infinito não é por isso um objecto imenso, que ultrapassa os horizontes do olhar. É o Desejo que mede a infinidade do infinito, porque ele constitui a medida pela própria impossibilidade de medida ${ }^{8}$.

Segundo o filósofo lituano, a base da experiência relacional é o Desejo. Este é compreendido como algo intrínseco à estrutura humana, algo que se revela como a "vocação por excelência" de todo ser, e que o conduz à compreensão de que ele não basta a si mesmo ${ }^{9}$. O Desejo não é mera necessidade, pois não é passível de satisfação, ao contrário, é uma "insaciedade" contínua em que o outro não vem para saciá-la, mas para confirmar que o eu precisa dele: “O Desejo é desejo do absolutamente Outro. Para além da fome que se satisfaz, da sede que se mata e dos sentidos que se apaziguam, a metafísica deseja o Outro para além das satisfações $[\ldots]^{\prime 10}$.

Em Levinas, o Desejo é essencialmente metafísico. Ele é "Desejo pelo Invisível”, "Desejo pelo Infinito", uma vez que o outro transcende todos as percepções de sentidos e cognitivas do eu. O Desejo conduz o eu em direção à relação de face a face com o outro, que, de forma semelhante ao eu, compartilha desse Desejo de ser humano em relação à alteridade de outro ser humano. É o Desejo que, na perspectiva levinasiana, proporciona à humanidade uma abertura para o insaciável apetite de bondade e generosidade $^{11}$.

Portanto, para a filosofia da alteridade, o Infinito estabelece como meta novos horizontes de busca pelo outro, ou seja, uma real abertura à alteridade daquele que se encontra na condição de ser Desejável, apesar de ser diferente e irredutível ao eu.

\section{Rosto e ética}

Em suas meditações, Emmanuel Levinas interpela o eu a "sair de si mesmo" para ir ao encontro do outro que é completamente transcendência e Infinito. Esse "sair de si mesmo" para uma relação de face a face com o outro constitui-se como o momento ético por excelência.

${ }^{7}$ LEVINAS, Emmanuel. Totalidade e infinito. Tradução José Pinto Ribeiro. Lisboa: Edições 70, 2008, p. 190.

${ }^{8}$ LEVINAS, Emmanuel. Totalidade e infinito. Tradução José Pinto Ribeiro. Lisboa: Edições 70, 2008, p. 50.

${ }^{9}$ Cf. LEVINAS, Emmanuel. Totalidade e infinito. Tradução José Pinto Ribeiro. Lisboa: Edições 70, 2008, p. 20.

${ }^{10}$ LEVINAS, Emmanuel. Totalidade e infinito. Tradução José Pinto Ribeiro. Lisboa: Edições 70, 2008, p. 20 - 21.

${ }^{11}$ LEVINAS, Emmanuel. Totalidade e infinito. Tradução José Pinto Ribeiro. Lisboa: Edições 70, 2008, p. 19 - 21.

\begin{tabular}{|c|c|c|c|c|c|}
\hline intuitio & $\begin{array}{c}\text { ISSN } \\
1983-4012\end{array}$ & Porto Alegre & Vol.8 $-\mathrm{N}^{\circ} .2$ & $\begin{array}{c}\text { Dezembro } \\
2015\end{array}$ & p.15-24 \\
\hline
\end{tabular}


Partindo dessa concepção, ele compreende que o rosto, para além de todas as manifestações concretas, é "expressão", em outros termos, o rosto é "interpelação ética", é "palavra": "O rosto fala. A manifestação do rosto é já discurso" ${ }^{12}$. Conforme a filosofia da alteridade, a expressão verbal que irrompe do rosto do outro é que torna possível o estabelecimento de uma relação ética. Esta expressão verbal assume sua forma no interdito ético-teológico "não matarás". Dessa forma: "ver um Rosto é já escutar: Tu não matarás!" 13.

Este interdito ético-teológico que surge do rosto desnudo do sujeito significa, para além do homicídio, negar o Infinito que se manifesta no outro. Esta expressão verbal impõe como exigência a impossibilidade de redução do outro ao mesmo. Nesse sentido, "não matarás" significa "não reduzirás o outro à ideia" 14: "O 'não matarás' não significa somente a interdição de enfiar uma faca no peito do próximo. Um pouco isso. Mas tantas maneiras de ser comportam uma forma de esmagar outrem" ${ }^{15}$.

Ao descrever esta lei/palavra que emerge do rosto do outro, Emmanuel Levinas utiliza-se da narrativa do fratricídio em Gênesis. Segundo o filósofo, mesmo após o assassinato de Abel, Caim não pôde desvencilhar-se da responsabilidade que o compelia. A voz de Deus continuou a interpelação de Abel: Não Matarás! ${ }^{16}$.

Na filosofia da alteridade, é impossível, mediante o olhar fenomenológico, transformar o rosto do outro em conteúdo. Desta forma, o rosto do outro é nu. O rosto expressa, exposto em sua fragilidade, uma mensagem pedagógica em que o eu é interpelado a ser justo e misericordioso. Levinas descreve o rosto do outro, em sua nudez e fragilidade, a partir da quadríade veterotestamentária: pobre, órfão, viúva e estrangeiro. Com efeito, Emmanuel Levinas conclui que do rosto nu, miserável e excluído do outro surge o apelo a uma responsabilidade indeclinável ${ }^{17}$.

Destarte, a relação do face a face proposta por Levinas constitui um apelo que desemboca numa responsabilidade infinita pelo outro. Nesse sentido, o ser humano, para a filosofia da alteridade, é um "serpara-o-outro" 18

\section{Rosto e responsabilidade}

\footnotetext{
${ }^{12}$ LEVINAS, Emmanuel. Totalidade e infinito. Tradução de José Pinto Ribeiro. Lisboa: Edições 70, 2008, p. 54.

${ }^{13}$ LEVINAS, Emmanuel. Totalidade e infinito. Tradução de José Pinto Ribeiro. Lisboa: Edições 70, 2008, p. 91.

${ }^{14}$ LEVINAS apud MELO, Nélio Vieira de. A Ética da alteridade em Emmanuel Levinas. Porto Alegre: EDIPUCRS; Recife: INSAF, 2003, p. 22.

${ }^{15}$ LEVINAS apud POIRIÉ, François. Emmanuel Lévinas: ensaio e entrevistas. Tradução de J. Guinsburg, et al. São Paulo: Perspectiva, 2007, p. 53.

${ }^{16}$ Cf. RIBEIRO JUNIOR, Nilo. Sabedoria de Amar: a ética no itinerário de Emmanuel Levinas. São Paulo: Loyola, 2005 , p. 67.

${ }^{17}$ Para a elaboração desta perspectiva, Levinas inspira-se na quadríade veterotestamentária: pobre, viúva, órfão e estrangeiro, que representa respectivamente os miseráveis e excluídos da sociedade hebraica.

${ }_{18}$ Expressão inspirada na máxima levinasiana "um-para-o-outro" (LEVINAS, Emmanuel. De Deus que vem à ideia. Tradução de Pergentino Stefano Pivatto (coord.). Petrópolis: Vozes, 2002. p. 112).
}

\begin{tabular}{|c|c|l|l|c|c|}
\hline intuitio & $\begin{array}{c}\text { ISSN } \\
1983-4012\end{array}$ & Porto Alegre & Vol.8 $-\mathrm{N}^{\mathrm{o}} .2$ & $\begin{array}{c}\text { Dezembro } \\
2015\end{array}$ & p.15-24 \\
\hline
\end{tabular}


De acordo com Emmanuel Levinas, o rosto que emerge no mundo vem a ser um convite à responsabilidade. Inspirado na célebre frase de Dostoievski, "Somos culpados de tudo e de todos perante todos, e eu mais que os outros" ${ }^{\prime 19}$, o filósofo em pesquisa propõe, como base das relações humanas, uma "ética da responsabilidade" "20: "O outro não está simplesmente próximo no espaço, ou próximo como um parente, mas que se aproxima essencialmente de mim enquanto me sinto- enquanto sou responsável por ele" 21 .

Com efeito, Emmanuel Levinas acredita que frente à face do outro, o ser humano é interpelado a responder não apenas por si próprio, mas é, anteriormente, conclamado a assumir uma responsabilidade infinita por outrem: "Entendo responsabilidade como responsabilidade pelo Outro, por aquilo que não é feito meu, ou por aquilo que nem sequer me importa; ou o que precisamente e realmente me importa é enfrentado por mim como face"22.

Em Levinas, a responsabilidade se interpreta como uma reação irrecusável à exigência ética presente no rosto do outro. Diante do rosto do outro o ser humano é convocado a agir de forma desinteressada e gratuita, sacrificando o seu bem pelo bem do outro. Nesse sentido, a relação ética é assimétrica, ou seja, irrecíproca:

Um dos temas fundamentais, de que ainda não falamos, de Totalidade e Infinito, é que a relação intersubjetiva é uma relação não-simétrica. Nesse sentido, sou responsável por outrem sem esperar a recíproca, ainda que isso viesse a me custar a vida. A recíproca é assunto dele" 23

Emmanuel Levinas acredita que não seria uma relação genuinamente ética agir esperando receber o mesmo que foi dado. Ele considera que tal postura seria abrir-se para um sentimento egocêntrico, em que o eu só percebe a si próprio. Diante dessas considerações, torna-se imprescindível esclarecer que a ética da responsabilidade não assume contornos herméticos. Ela não se limita a um "egoísmo a dois". A filosofia levinasiana convoca o indivíduo a assumir a responsabilidade pelo próximo do próximo. E, ao tratar deste assunto, Levinas instaura a presença de um “terceiro" na relação ética ${ }^{24}$.

${ }^{19}$ DOSTOIEVSKI apud HUTCHENS, B.C. Compreender Lévinas. Tradução de Vera Lúcia Mello Jocelyne. Petrópolis: Vozes, 2007, p. 44.

${ }^{20}$ Cf. HUTCHENS, B.C. Compreender Lévinas. Tradução de Vera Lúcia Mello Jocelyne. Petrópolis: Vozes, 2007, 2007, p. 44.

${ }^{21}$ LEVINAS, Emmanuel. Totalidade e infinito. Tradução de José Pinto Ribeiro. Lisboa: Edições 70, 2008, p. 182.

${ }^{22}$ LEVINAS HUTCHENS, B.C. Compreender Lévinas. Tradução de Vera Lúcia Mello Jocelyne. Petrópolis: Vozes, 2007, p. 33-34.

${ }^{23}$ Cf. LEVINAS, Emmanuel. Ética e infinito: diálogos com Philippe Nemo. Tradução de João Gama. Lisboa: Ed. 70, 1982, p. 74.

${ }^{24}$ LEVINAS, Emmanuel. Ética e infinito: diálogos com Philippe Nemo. Tradução de João Gama. Lisboa: Ed. 70, 1982, 52.

\begin{tabular}{|c|c|c|c|c|c|}
\hline intuitio & $\begin{array}{c}\text { ISSN } \\
1983-4012\end{array}$ & Porto Alegre & Vol.8 $-\mathrm{N}^{\mathrm{o} .2}$ & $\begin{array}{c}\text { Dezembro } \\
2015\end{array}$ & p.15-24 \\
\hline
\end{tabular}


O terceiro pelo qual o eu é radicalmente responsável evoca a humanidade como um todo. Este outrem, enquanto raça humana, conclama o eu a uma responsabilidade indeclinável, baseada na fraternidade, honestidade, paz e, especialmente, na noção de justiça.

Emmanuel Levinas compreende o conceito de "fazer-se justo" como estabelecimento da prioridade do outro antes do eu. Este princípio ético é instituído como ideal que conduz o eu em direção a uma batalha contra o egoísmo encarnado, que não reconhece o clamor por misericórdia emergente no rosto do outro:

Ouvir a sua miséria que clama justiça não consiste em representar-se uma imagem, mas em colocar-se como responsável, ao mesmo tempo como mais e como menos do que o ser que se apresenta no rosto. Menos porque o rosto me chama às minhas obrigações e me julga. O ser que nele se apresenta vem de uma dimensão de altura, dimensão da transcendência onde pode apresentar-se como estrangeiro, sem se opor a mim, como obstáculo ou inimigo. Mas, porque a minha posição de eu consiste em poder responder à miséria essencial de outrem, em encontrar recursos ${ }^{25}$.

$\mathrm{Na}$ filosofia da alteridade, só existe justiça quando a responsabilidade radical por outrem invade todas as estruturas do ser humano. Para além de um ser-com-os-outros, o ser humano é, como descrito anteriormente, um ser-para-os-outros. Destarte, renunciar à responsabilidade por outrem significa negar a si mesmo, a sua própria constituição no mundo.

\section{Rosto e religião}

A proposta de uma relação ética como resposta ao clamor que emana da face humana é interpretada pela filosofia da alteridade como uma verdadeira experiência religiosa. Por meio do acesso ao rosto do outro irrompe uma ideia acerca de Deus:

Reviravolta a partir do rosto de outrem onde, no próprio âmago do fenômeno, na sua luz própria, significa um excedente de Significância que se poderia designar por glória. Ela me suplica, me reclama, me convoca. Não se poderia chamar palavra de Deus esta súplica ou esta interpelação ou esta convocação à responsabilidade? Não é precisamente nesta convocação que Deus vem à ideia, antes que na tematização do pensável, antes mesmo do que num convite a qualquer diálogo? ${ }^{26}$

\footnotetext{
${ }^{25}$ LEVINAS, Emmanuel. Totalidade e infinito. Tradução de José Pinto Ribeiro. Lisboa: Edições 70, 2008, p. 182, p. 211.

${ }^{26}$ LEVINAS, Emmanuel. Entre Nós: Ensaios sobre a alteridade. Tradução de Pergentino Stefano Pivatto (coord.) Petrópolis: Vozes, 1997, p. 196.
}

\begin{tabular}{|c|c|c|c|c|c|}
\hline intuitio & $\begin{array}{c}\text { ISSN } \\
1983-4012\end{array}$ & Porto Alegre & Vol.8 $-\mathrm{N}^{\mathrm{o}} .2$ & $\begin{array}{c}\text { Dezembro } \\
2015\end{array}$ & p.15-24 \\
\hline
\end{tabular}


Embora a discussão acerca de Deus e de sua revelação não tenha sido uma preocupação $a$ priori, a tentativa levinasiana de estabelecer o ser para "o além da essência" culminou com a identificação de Deus como esse "mais além" 27 que, conforme o autor, se revelaria no rosto do outro.

Ao lidar com a questão do religioso, a filosofia do rosto procura superar a dicotomia fé e razão, propondo uma fusão, entre ambas, na relação ética. Esta proposta exprime uma evidente intencionalidade de realizar uma grande síntese entre as tradições bíblico-talmúdicas e a filosofia de vertente grega, rompendo assim, com a antiga separação entre o Deus dos filósofos do Deus de Abraão, Isaque e Jacó ${ }^{28}$.

Destarte, Emmanuel Levinas interpreta a experiência religiosa como uma concreção de ordem ética, ou seja, o autor compreende a religião como ética e a ética como religião. Ao instaurar a religião como uma instância ética, ele propôs uma alternativa ao discurso religioso, sem, contudo, culminar em uma objetivação da divindade ou mesmo em uma alienação e desvalorização do mundo, como ocorre no dualismo platônico.

Para Levinas, a experiência religiosa é, entre outras dimensões, uma negação de todas as formas de solipsismo, ou seja, ela é essencialmente fome pelo outro. Com efeito, a religião é ética, e ética é testemunho profético:

Assumir a responsabilidade por outrem é para todo homem, uma maneira de testemunhar a glória do Infinito, de ser inspirado. Há profetismo, há inspiração no homem que responde por outrem, paradoxalmente, mesmo antes de saber o que, concretamente se exige dele. Esta responsabilidade anterior à Lei é revelação de Deus. ${ }^{29}$

Em Levinas, o discurso acerca de Deus irrompe no instante em que o eu assume sua responsabilidade radical pelo outro. Ele acredita que atentar-se para o religioso significa assumir uma postura de entrega total, atendendo, dessa forma, ao interdito ético-teológico que emana da face humana. Com efeito, Emmanuel Levinas estabelece uma relação intrínseca entre o ético-religioso e o transcendente. Por meio da experiência de concretude ética, a filosofia da alteridade estabelece um ponto de convergência entre transcendência e imanência:

Aquele que denominamos Deus não pode ter sentido senão a partir dessas relações (relações humanas) distintas. Somente a partir de tais relações Deus pode manifestar-se. Pensar em Deus sem que esta ideia adote um modelo em

${ }^{27}$ Cf. VÁZQUEZ, Moro Ulpiano. A teologia interrompida: para uma interpretação de E. Levinas. Perspectiva Teológica, n. 14, 1982, p. 59.

${ }^{28}$ Cf. PIVATTO, Pergentino Stefano. Ética da alteridade. In: OLIVEIRA, Manfredo. Correntes fundamentais da ética contemporânea. 2. ed. Petrópolis: Vozes, 2001, p. 179.

29 . LEVINAS, Emmanuel. Ética e infinito: diálogos com Philippe Nemo. Tradução de João Gama. Lisboa: Ed. 70, 1982, p. 107.

\begin{tabular}{|c|c|l|l|c|c|}
\hline intuitio & $\begin{array}{c}\text { ISSN } \\
1983-4012\end{array}$ & Porto Alegre & Vol.8 $-\mathrm{N}^{\mathrm{o}} .2$ & $\begin{array}{c}\text { Dezembro } \\
2015\end{array}$ & p.15-24 \\
\hline
\end{tabular}


relação de imanência é um pensamento imediatamente contraditório. Não existe um modelo de transcendência fora da ética. ${ }^{30}$

Na filosofia do rosto, Deus não se distancia do cotidiano, mas se aproxima do eu, uma vez que o outro é sua exponencial manifestação. A relação ética, experiência metafísica por excelência, manifesta concretamente a própria transcendência de um Deus que optou por se revelar à humanidade:

Outrem é o próprio lugar da verdade metafísica e indispensável à minha relação com Deus. Não desempenha de modo nenhum o papel de mediador. Outrem não é encarnação de Deus, mas precisamente pelo seu rosto, em que está desencarnado, a manifestação da altura em que Deus se revela. ${ }^{31}$

Nesse sentido, o rosto do outro postula uma significação ímpar e extraordinária, que Levinas chama de "traço". Ele acredita que a revelação de Deus, presente na face humana, é uma espécie de vestígio, marca deixada pelo Infinito. Por meio desta compreensão de revelação como vestígio, Levinas, de forma intrigante, afirma o outro como imagem de Deus, sem, contudo, permitir com que este outro seja transformado em ícone da divindade

\section{Considerações finais}

O objetivo deste artigo consistiu em realizar uma concisa introdução à noção de rosto na ética da alteridade e ao seu apelo à responsabilidade radical por outrem. Conforme Levinas, a produção de sentido surge a partir das relações humanas. Transcendendo a simples abordagem solipsista e especulativa do conhecimento, o saber é interpretado como algo que irrompe da penúria do rosto do outro. Nesse sentido, o outro é compreendido como lugar originário da produção do conhecimento.

A partir de um humanismo ético e religioso, as relações humanas recebem um novo significado à luz da compreensão de que o ser humano é um "ser-para-os-outros". Segundo a filosofia da alteridade, o rosto nu do outro interpela o ser humano a assumir uma postura de responsabilidade radical e assimétrica pelo outro.

Emmanuel Levinas compreende a experiência religiosa como uma concreção de ordem ética. Com efeito, em face da experiência de concretude ética, a filosofia da alteridade estabelece um ponto de convergência para o clássico dilema da transcendência e da imanência de Deus.

Dessarte, este novo paradigma ético-epistemológico estabelece vários desafios para a sociedade contemporânea. A academia filosófica se depara com o desafio de construir um conhecimento mais

30 LEVINAS, apud MELO, Nélio Vieira de. A Ética da alteridade em Emmanuel Levinas. Porto Alegre: EDIPUCRS; Recife: INSAF, 2003, p. 132.

${ }^{31}$ LEVINAS, Emmanuel. Ética e infinito: diálogos com Philippe Nemo. Tradução de João Gama. Lisboa: Ed. 70, 1982, p. 68.

\begin{tabular}{|c|c|c|c|c|c|}
\hline intuitio & $\begin{array}{c}\text { ISSN } \\
1983-4012\end{array}$ & Porto Alegre & Vol.8 $-\mathrm{N}^{\mathrm{o}} .2$ & $\begin{array}{c}\text { Dezembro } \\
2015\end{array}$ & p.15-24 \\
\hline
\end{tabular}


relacional, dialogal e menos fechado, fragmentado e isolado em "guetos", e a religião, por sua vez, é interpelada a responder a essa ética emergente. Com efeito, as relações sociais recebem um novo significado à luz da compreensão de que o ser humano é um ser essencialmente responsável pelos outros. A partir do rosto nu do outro, o ser humano é interpelado a ser solidário, justo e misericordioso.

\section{Referências}

BUCKS, René. A Bíblia e a ética: A relação entre a filosofia e a Sagrada Escritura na obra de Emmanuel Levinas. São Paulo: Loyola, 1997.

HUTCHENS, B.C. Compreender Lévinas. Tradução de Vera Lúcia Mello Jocelyne. Petrópolis: Vozes, 2007.

LEVINAS, Emmanuel. Totalidade e infinito. Tradução de José Pinto Ribeiro. Lisboa: Edições 70, 2008 . Ética e infinito: diálogos com Philippe Nemo. Tradução de João Gama. Lisboa: Ed. 70, 1982.

1997.

Entre Nós: Ensaios sobre a alteridade. Tradução de Pergentino Stefano Pivatto (coord.) Petrópolis: Vozes,

De Deus que vem à ideia. Tradução de Pergentino Stefano Pivatto (coord.). Petrópolis: Vozes, 2002.

Humanismo do outro homem. Tradução de Pergentino S. Pivato (coord.). Petrópolis: Vozes, 1993.

MELO, Nélio Vieira de. A Ética da alteridade em Emmanuel Levinas. Porto Alegre: EDIPUCRS; Recife: INSAF, 2003.

PIVATTO, Pergentino Stefano. Ética da alteridade. In: OLIVEIRA, Manfredo. Correntes fundamentais da ética contemporânea. 2. ed. Petrópolis: Vozes, 2001. p. 78-97.

POIRIÉ, François. Emmanuel Lévinas: ensaio e entrevistas. Tradução de J. Guinsburg, et al. São Paulo: Perspectiva, 2007.

RIBEIRO JUNIOR, Nilo. Sabedoria de Amar: a ética no itinerário de Emmanuel Levinas. São Paulo: Loyola, 2005. VÁZQUEZ, Moro Ulpiano. A teologia interrompida, para uma interpretação de E. Levinas. Perspectiva Teológica, n. 14, p. $51-73,1982$.

Recebido em: 17/12/2014

Aprovado para a publicação em: 19/11/2015

\begin{tabular}{|c|c|l|l|c|c|}
\hline intuitio & $\begin{array}{c}\text { ISSN } \\
1983-4012\end{array}$ & Porto Alegre & Vol.8 $-\mathrm{N}^{\circ} .2$ & $\begin{array}{c}\text { Dezembro } \\
2015\end{array}$ & p.15-24 \\
\hline
\end{tabular}

